\title{
PENGARUH CONTRACTING CONTINYU SEBUAH PENDEKATAN BEHAVIORISTIK DALAM MENINGKATKAN SELF AWARNES
}

\author{
Muhammad Ilham Bakhtiar ${ }^{1)}$ \\ STKIP Andi Matappa, Jl. Andi Maura, Kabupaten Pangkep \\ Email: ilham_konseling@yahoo.com \\ Andi Aztri Fithrayani ${ }^{2)}$ \\ STKIP Andi Matappa, Jl. Andi Maura, Kabupaten Pangkep \\ e-mail: a.aztri_fithrayani@yahoo.com
}

\begin{abstract}
The purpose of this study was to determine the effect of the contract method (Contingency Contracting) to increase students' awareness on the rule of order at SMA Negeri 1 Tanete Rilau. This research is quantitative with the entire population of students of class X and XI SMA Negeri 1 Tanete Rilau are 408 people with a sample of 42 people. Questionnaire data collection techniques are, and observation. The results of this study are calculated turns Fhitung $\geq$ After Ftabel or $4.42 \geq 3.23$, then reject Ho and accept H1 means that a significant difference between the methods of contract (Contingency Contracting) to increase students' self awarnes.
\end{abstract}

Keywords: methods of contract and student awareness

\begin{abstract}
Abstrak. Tujuan penelitian ini adalah Untuk mengetahui pengaruh metode kontrak (Contracting Contingency) terhadap peningkatan kesadaran siswa pada peraturan tata tertib di SMA Negeri 1 Tanete Rilau. Penelitian ini merupakan kuantitatif dengan Populasi seluruh siswa kelas X dan XI SMA Negeri 1 Tanete Rilau yaitu 408 orang dengan sampel 42 orang. Teknik pengumpulan data adalaha Angket, dan observasi. Hasil penelitian ini adalah Setelah dihitung ternyata $F_{\text {hitung }} \geq F_{\text {tabel }}$ atau 4,42 $\geq 3,23$, maka tolak $\mathrm{H}_{\mathrm{o}}$ dan terima $\mathrm{H}_{1}$ artinya terdapat pengaruh yang signifikan antara metode kontrak (Contracting Contingency) terhadap peningkatan self awarnes siswa.
\end{abstract}

Katakunci: metode kontrak dan kesadaran siswa

\section{PENDAHULUAN}

Peran pendidikan di sekolah untuk mengembangkan pribadi siswa secara menyeluruh, serta memperoleh ilmu pengetahuan dan melaksanakan pendidikan kecerdasan yang dapat dipertanggung jawabkan keberhasilannya melalui ujian. Siswa dituntut untuk mencapai hasil belajar optimal dan meningkatkan kesadaran diri siswa untuk mentaati peraturan tata tertib sekolah.
Pencapaian hasil belajar optimal dan kedisiplinan siswa selain ditentukan oleh kecerdasan yang tinggi, juga didukung oleh adanya kesadaran (awarness) siswa dalam mentaati peraturan tata tertib di sekolah demikian sebaliknya jika siswa tidak memiliki kesadaran diri (self awerness) tentinya memiliki prilaku yang tidak baik.

Ezra \& Ezra (2007) menjelaskan bahwa apabila seseorang kurang memiliki Self 
awareness sering membuat tidak percaya diri, suka bersikap plin plan, tidak punya prinsip yang kuat, sulit menetapkan tujuan dan target yang ingin dicapai, karena banyak potensi dan bakat yang dimiliki hanya terpendam saja dan tidak dikembangkan.

Melihat hal ini tentunya perhatian guru sangat besar kepada siswa, diharapkan siswa dapat memiliki kesadaran diri (self awernes) agar siswa dapat memiliki prinsip yang kuat dan jelas khususnya dalam menjalani aturan sekolah dalam mencapai prestasinya.

Menurut Ahmadi (2009:142) bahwa :Perhatian berhubungan erat dengan kesadaran jiwa terhadap suatu objek yang direaksi pada suatu waktu. Terang tidaknya kesadaran kita terhadap suatu objek tertentu tidak tetap, ada kalanya kesadaran kita meningkat (menjadi terang), dan ada kalanya menurun (menjadi samar-samar). Keadaaan lapangan kesadaran dan kekuatannya tidak tetap pula, kadangkadang luas dan kadang-kadang menjadi sempit. Hal itu tergantung pada pengerahan aktivitas jiwa terhadap objek tersebut.

Penjelasan di atas menguraikan bahwa taraf kesadaran kita akan meningkat kalau jiwa kita dalam mereaksi sesuatu meningkat juga. Apabila taraf kekuatan kesadaran kita naik atau menjadi giat karena sesuatu sebab maka kita berada pada permulaan perhatian. Perhatian timbul dengan adanya pemusatan kesadaran kita terhadap sesuatu.
Siswa yang memiliki kesadaran diri yang tinggi pada peraturan tata tertib sekolah akan mampu menampilkan perilaku sesuai dengan batasan-batasan, norma yang berlaku, dan mampu mengarahkan dirinya kepada aktivitas-aktivitas yang positif dalam lingkungan kelas maupun lingkungan sekolah. Siswa yang tidak ditanamkan kesadaran pada peraturan tata tertib sekolah, maka akan mengalami kegagalan dalam mencapai perkembangan jati dirinya atau rasa kedisiplinan dalam mentaati peraturan sekolah.

Dalam proses pendidikan di sekolah, kita mengenal siswa bermasalah, siswa seperti ini adalah siswa yang selalu melanggar peraturan tata tertib sekolah. Tata tertib sekolah hanya dianggap sebagai aturan biasa yang tidak mesti diikuti, anak yang sering melanggar tata tertib sekolah bisa jadi memiliki persoalan di rumah, dengan keluarga, atau lingkungannya. Hal ini akan berdampak buruk pada siswa yang lain dan tentu saja dengan perilaku mereka pada akhirnya.

Dengan memahami kondisi siswa yang sering melanggar, maka guru bimbingan dan konseling dapat memberikan metode kontrak (Contracting Contingency) agar siswa dapat meningkatkan kesadaran akan tanggung jawab pada peraturan tata tertib di sekolah. (Fauzan:2016).

Contracting Contingency merupakan proses pembentukan perilaku melalui sebuah kontrak atau sebuah perjanjian yang sudah disepakati oleh guru dan siswa dengan tujuan agar siswa lebih meningkatkan kesadaran diri pada peraturan tata tertib sekolah melalui proses 
perjanjian dan diperkuat oleh konsekuensi dari perjanjian tersebut.

Manfaat dari metode kontrak (Contracting Contingency) antara lain memberikan motivasi dalam diri siswa untuk lebih meningkatkan kesadaran terhadap peraturan sekolah dan menurunkan perilaku seringnya melakukan pelanggaran tata tertib sekolah secara satu persatu maupun secara bersamaan dengan kontrak yang disepakati serta konsekuensi dari kontrak tersebut. (Fauzan:2016)

Metode kontrak diharapkan dapat meningkatkan kesadaran siswa dalam mentaati peraturan tata tertib sekolah. Kaitan antara Contracting Contingency dengan kesadaran adalah dalam Contracting Contingency terdapat persetujuan kontrak antara guru dan siswa sesuai dengan kesepakatan bersama untuk meningkatkan kesadaran siswa terutama dalam meningkatkan kesadaran pada peraturan tata tertib siswa. Namun tidak bisa dipungkiri bahwa ada saja siswa yang akan melanggar perjanjian dan siswa merasa bahwa konsekuensi dari metode kontrak tersebut dapat memberatkan dirinya. Oleh karena itu, guru bimbingan dan konseling harus memberikan pemahaman lebih mendalam kepada siswa bagaimana bentuk dan tujuan dari metode kontrak sehingga siswa lebih mengerti serta memahami tujuan dari metode tersebut.

Melihat persoalan di atas, maka penulis ingin menggali lebih dalam bagaimana metode kontrak (Contracting Contingency) dapat meningkatkan kesadaran siswa pada peraturan tata tertib di sekolah dalam suatu karya tulis ilmiah dengan judul Pengaruh metode kontrak (Contacting Contingency) terhadap peningkatan kesadaran siswa pada peraturan tata tertib di SMA Negeri 1 Tanete Rilau.

Adapun tujuan penelitian ini adalah "Untuk mengetahui pengaruh metode kontrak (Contracting Contingency) terhadap peningkatan kesadaran siswa pada peraturan tata tertib di SMA Negeri 1 Tanete Rilau."

\section{METODE}

Dalam penelitian ini digunakan metodologi dengan pendekatan kuantitatif.

Seorang peneliti harus mengumpulkan data setepat-tepatnya dan selengkaplengkapnya dari kasus tersebut untuk mengetahui sebab-sebab sesungguhnya. Data yang terkumpul disusun dan dipelajari menurut urutannya dan dihubungkan satu sama lain secara menyeluruh dan integral agar menghasilkan gambaran umum dari kasus yang diteliti.

Penelitian ini adalah paradigma ganda yaitu 2 variabel dependen (terikat) $X_{1}$ dan $X_{2}$ variabel independen (bebas) $\mathrm{Y}$, variabel $\mathrm{X}_{1}$ adalah Metode Kontrak, variabel $\mathrm{X}_{2}$ adalah Kesadaran Siswa, dan variabel Y adalah Tata Tertib. Desain penelitiannya adalah sebagai berikut: 


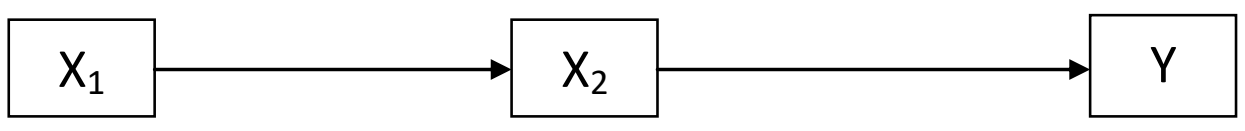

Gambar 2. Desain Penelitian

Keterangan :

$\mathrm{X}_{1}=$ Metode Kontrak

$\mathrm{X}_{2}=$ Kesadaran Siswa

$\mathrm{Y}=$ Tata Tertib

Populasi dalam penelitian ini adalah metode kontrak (Contracting Contingency) seluruh siswa kelas X dan XI SMA Negeri 1 terhadap peningkatan kesadaran siswa pada Tanete Rilau yaitu 408 orang dengan sampel 42 peraturan tata tertib di SMA Negeri 1 Tanete orang. Sampel dalam penelitian ini adalah $10 \%$ Rilau, dengan demikian yang menjadi variabel dari jumlah keseluruhan siswa dengan sistem random sampling. Teknik pengumpulan data $\mathrm{X}_{1}$ adalah pengaruh metode kontrak (Contracting Contingency), variabel $\mathrm{X}_{2}$ adalah adalaha Angket, dan observasi.(Arikunto. 2002) kesadaran siswa dan variabel $\mathrm{Y}$ adalah tata

Analisis data yang dipakai adalah tertib, menurut Riduwan (2007:141) digunakan analisis data untuk mencari adakah pengaruh rumus Korelasi ganda, sebagai berikut:

$$
R_{X 1 . X 2 . Y}=\sqrt{\frac{r_{X 1 . Y}^{2}+r_{X 2 . Y}^{2}-2\left(r_{X 1 . Y}\right) \cdot\left(r_{X 2 . Y}\right) \cdot\left(r_{X 1 . X 2}\right)}{1-r_{X 1 . X 2}^{2}}}
$$

Selanjutnya untuk mengetahui signifikansi korelasi ganda dicari dulu $\mathrm{F}_{\text {hitung }}$ kemudian dibandingkan dengan $\mathrm{F}_{\text {tabel }}$

$$
F_{\text {hitung }}=\frac{\frac{R^{2}}{k}}{\frac{\left(1-R^{2}\right)}{n-k-1}}
$$

Dimana : $\quad \mathrm{R}=$ Nilai Koefisien

Korelasi Ganda

dihitung

$$
\begin{aligned}
& \mathrm{k}=\text { Jumlah variable Bebas } \\
& \mathrm{n}=\text { Jumlah sampel } \\
& \mathrm{F}_{\text {hitung }}=\text { Nilai F yang }
\end{aligned}
$$

Kaidah pengujian signifikansi:

Jika $\mathrm{F}_{\text {hitung }} \geq \mathrm{F}_{\text {tabel, }}$ maka tolak Ho artinya signifikan dan
Jika $\mathrm{F}_{\text {hitung }} \leq \mathrm{F}_{\text {tabel }}$, maka terima Ho artinya tidak signifikan

Nilai $F_{\text {tabel }}$ akan dicari dengan menggunakan tabel $\mathrm{F}$ dengan rumus signifikan; $\dot{\alpha}=0,01$ atau 0,05

$$
\mathrm{F}_{\text {tabel }}=\mathrm{F}_{(1-\grave{\alpha})(\mathrm{dk}=\mathrm{k}),(\mathrm{dk}=\mathrm{n}-\mathrm{k} 1)}
$$

(Riduwan, 2007:142) 


\section{HASIL DAN PEMBAHASAN}

Berdasarkan hasil penenelitian dengan menggunakan konstruksi angket, maka akan didapatkan 4 jenis data sebagai berikut:

1. Variabel Metode Kontrak $\left(\mathrm{X}_{1}\right)$

2. Variabel Kesadaran Siswa $\left(X_{2}\right)$

3. Variabel Tata Tertib (Y)

4. Sampel sebanyak $(n=42)$

Dengan penyebaran angket pada 42 responden, maka dapat ditabulasikan hasil penelitian sebagai berikut:

\section{1) Mencari nilai korelasi $X_{1}$ terhadap $Y$}

Dapat diketahui bahwa $\mathrm{n}$ merupakan jumlah responden, dan $\sum \mathrm{X}_{1}$ adalah jumlah nilai pada variabel metode kontrak setelah di hitung dari skala likert, dan $\sum y$ adalah nilai tata tertib. jumlah $\mathrm{X}_{1} \mathrm{Y}$ dapat dilihat pada tabel berikut ini:

\begin{tabular}{c|c}
\hline $\begin{array}{c}\text { Simbol } \\
\text { statistic }\end{array}$ & nilai statistik \\
\hline $\mathrm{N}$ & 42 \\
\hline$\sum \mathrm{X}_{1}$ & 1177 \\
\hline$\sum \mathrm{y}$ & 1226 \\
\hline$\sum \mathrm{X}_{1}{ }^{2}$ & 33307 \\
\hline$\sum \mathrm{Y}^{2}$ & 36102 \\
\hline$\sum \mathrm{X}_{1} \mathrm{Y}$ & 34451 \\
\hline
\end{tabular}
Dengan demikian, hasil pemangkatan dan

$$
r_{X 1 . Y}=\frac{1446942-1443002}{\sqrt{\{1398894-1385329\}\{.\{1516284-1503076\}}}
$$

$$
\begin{aligned}
& r_{X 1 . Y}=\frac{3940}{\sqrt{\{13565\} .\{13208\}}} \\
& r_{X 1 . Y}=0,2
\end{aligned}
$$

\section{2) Mencari nilai korelasi $X_{2}$ terhadap $Y$}

Dapat diketahui bahwa $\mathrm{n}$ merupakan jumlah responden, dan $\sum \mathrm{X}_{2}$ adalah jumlah nilai kesadaran siswa setelah di hitung dari skala likert, dan $\sum y$ adalah nilai tata tertib. Dengan demikian, hasil pemangkatan dan penjumlahan untuk mengetahui nilai $\mathrm{X}_{2} \mathrm{Y}$ dapat dilihat pada tabel berikut ini:

\begin{tabular}{c|c}
\hline $\begin{array}{c}\text { Simbol } \\
\text { statistik }\end{array}$ & nilai statistik \\
\hline $\mathrm{N}$ & 42 \\
\hline$\sum \mathrm{X}_{2}$ & 1130 \\
\hline$\sum \mathrm{y}$ & 30858 \\
\hline$\sum \mathrm{X}_{2}{ }^{2}$ & 36102 \\
\hline$\sum \mathrm{Y}^{2}$ & 33152 \\
\hline$\sum \mathrm{X}_{2} \mathrm{Y}$ & Dengan Korelasi Ganda \\
\hline & $n\left(\sum X_{2} Y\right)-\left(\sum X_{2}\right) \cdot\left(\sum Y\right)$ \\
$r_{X 2 . Y}=\frac{\sqrt{\left\{n \cdot \sum X_{2}^{2}-\left(\sum X_{2}\right)^{2}\right\} \cdot\left(n \cdot \sum Y^{2}-\left(\sum Y\right)^{2}\right\}}}{}$
\end{tabular}

Dengan Korelasi Ganda

$$
r_{X 1 . Y}=\frac{n\left(\sum X_{1} Y\right)-\left(\sum X_{1}\right) \cdot\left(\sum Y\right)}{\sqrt{\left\{n \cdot \sum X_{1}^{2}-\left(\sum X_{1}\right)^{2}\right\} \cdot\left\{n \cdot \sum Y^{2}-\left(\sum Y\right)^{2}\right\}}} r_{X 2 . Y}=\frac{\sqrt{\left\{42.30858-(1130)^{2}\right\} \cdot\left\{42.36102-(1226)^{2}\right\}}}{\sqrt{\{1296036-1276900\})\{1516284-1503076}\}}
$$$$
r_{X 2 . Y}=\frac{42(33152)-(1130)(1226)}{\sqrt{\left\{42.30858-(1130)^{2}\right\} .\left\{42.36102-(1226)^{2}\right\}}}
$$

$$
r_{X 1 . Y}=\frac{42(34451)-(1177)(1226)}{\sqrt{\left\{42.33307-(1177)^{2}\right\} .\left\{42.36102-(1226)^{2}\right\}}}
$$

$$
\begin{aligned}
r_{X 2 . Y} & =\frac{7004}{\sqrt{\{19136\} .\{13208\}}} \\
r_{X 2 . Y} & =0,4
\end{aligned}
$$




\section{3) Mencari nilai korelasi $X_{1}$ terhadap}

$\mathbf{X}_{2}$

Untuk mengetahui nilai korelasi anatara kedua $\mathrm{X}$ yang saling mempengaruhi dapat dijelaskan sebagai berikut:

Dapat diketahui bahwa $\mathrm{n}$ merupakan jumlah responden, $\sum \mathrm{X}_{1}$ adalah jumlah nilai metode kontrak dan $\sum X_{2}$ adalah jumlah nilai kesadaran siswa setelah di hitung dari skala likert. Dengan demikian, hasil pemangkatan dan jumlah $\mathrm{X}_{1} \mathrm{X}_{2}$ dapat dilihat pada tabel berikut ini:

\begin{tabular}{c|c}
\hline $\begin{array}{c}\text { Simbol } \\
\text { statistik }\end{array}$ & nilai statistik \\
\hline $\mathrm{N}$ & 42 \\
\hline$\sum \mathrm{X}_{1}$ & 1177 \\
\hline$\sum \mathrm{X}_{2}$ & 1130 \\
\hline$\sum \mathrm{X}_{1}{ }^{2}$ & 33307 \\
\hline$\sum \mathrm{X}_{2}{ }^{2}$ & 30858 \\
\hline$\sum \mathrm{X}_{1} \mathrm{X}_{2}$ & 31881 \\
\hline
\end{tabular}

Dengan Korelasi Ganda

$$
r_{X 1 . x 2}=\frac{n\left(\sum X_{1} X_{2}\right)-\left(\sum X_{1}\right) \cdot\left(\sum X_{2}\right)}{\sqrt{\left\{n \cdot \sum X_{1}^{2}-\left(\sum X_{1}\right)^{2}\right\}:\left\{n \cdot \sum X_{2}^{2}-\left(\sum X_{2}\right)^{2}\right\}}}
$$$$
r_{X 1 . X 2}=\frac{42(31881)-(1177)(1130)}{\sqrt{\left\{42.33307-(1177)^{2}\right\} .\left\{42.30858-(1130)^{2}\right\}}}
$$

$$
\begin{aligned}
& r_{X 1 . X 2}=\frac{1339002-1330010}{\sqrt{\{13565\} \cdot\{19136\}}} \\
& r_{X 1 . X 2}=\frac{8992}{\sqrt{\{13565\} \cdot\{19136\}}} \\
& r_{X 1 . X 2}=0,05
\end{aligned}
$$

4) Mencari nilai korelasi antara variabel dan korelasi ganda $\left(\mathbf{R x}_{1} \cdot \mathbf{x}_{2} \cdot \mathbf{y}\right)$

\section{Ringkasan hasil korelasi}

\begin{tabular}{c|c}
\hline simbol statistik & nilai statistik \\
& \\
\hline $\mathrm{r}_{\mathrm{x} 1 . \mathrm{y}}$ & 0,2 \\
\hline $\mathrm{r}_{\mathrm{x} 2 . \mathrm{y}}$ & 0,4 \\
\hline $\mathrm{r}_{\mathrm{X} 1 . \mathrm{X} 2}$ & 0,05 \\
\hline
\end{tabular}

Dari hasil korelasi kemudian dimasukkan pada rumus korelasi ganda (R) dengan rumus:

$$
\begin{aligned}
& R_{X 1 . X 2 . Y}= \\
& \sqrt{\frac{r_{X 1 . Y}^{2}+r_{X 2 . Y}^{2}-2\left(r_{X 1 . Y}\right) \cdot\left(r_{X 2 . Y}\right) \cdot\left(r_{X 1 . X 2}\right)}{1-r_{X 1 . X 2}^{2}}} \\
& \sqrt{\frac{0,2^{2}+0,4^{2}-2(0,2) \cdot(0,4) \cdot(0,05)}{1-0,05^{2}}} \\
& R_{X 1 . X 2 . Y}= \\
& R_{X 1 . X 2 . Y}=\sqrt{\frac{0,20-0.008}{0,9975}}
\end{aligned}
$$

$$
\begin{aligned}
& R_{X 1 . X 2 . Y}=\sqrt{\frac{0.192}{0.9975}} \\
& R_{X 1 . X 2 . Y}=\sqrt{0,19} \\
& R_{X 1 . X 2 . Y}=0,43
\end{aligned}
$$

\section{5) Menguji signifikansi dengan rumus} $F_{\text {hitung: }}$

$$
\begin{aligned}
F_{\text {hitung }} & =\frac{\frac{R^{2}}{k}}{\frac{\left(1-R^{2}\right)}{n-k-1}}=\frac{\frac{0,43^{2}}{2}}{\frac{\left(1-0,43^{2}\right)}{42-2-1}}= \\
\frac{0,09245}{0,0209}= & 4,42
\end{aligned}
$$

Hipotesis dalam penelitian ini adalah “Ada Pengaruh Metode Kontrak (Contracting Contingency) Terhadap Peningkatan Kesadaran 
Siswa pada Peraturan Tata Tertib di SMA Negeri 1 Tanete Rilau. Untuk menguji hipotesis ini, maka hipotesis ini akan diubah menjadi hipotesis statistik dengan ketentuan sebagai berikut:

$\mathrm{Ha}=$ adalah hipotesis alternatif

Ho = adalah hipotesis nihil, pengujian statistik hanya menguji hipotesis nihil (Ho). Karena hipotesis nihil merupakan pernyataan tentang parameter yang bertentangan dengan keyakinan peneliti, apabila dari pengujian diperoleh keputusan yang mendukung atau setuju dengan Ho, maka dapat dikatakan Ho diterima.

Pada penelitian ini yang menjadi hipotesisi statistik adalah:

$\mathrm{Ha}=$ Terdapat pengaruh yang signifikan antara metode kontrak (Contracting Contingency) terhadap peningkatan kesadaran siswa pada peraturan tata tertib di SMA Negeri 1 Tanete Rilau.

Ho $=$ Tidak terdapat pengaruh yang signifikan antara metode kontrak (Contracting Contingency) terhadap peningkatan kesadaran siswa pada peraturan tata tertib di SMA Negeri 1 Tanete Rilau.

Kaidah pengujian signifikansi :

Jika Fhitung $\geq$ Ftabel, maka tolak Ho artinya signifikan dan

Jika Fhitung $\leq$ Ftabel, maka terima Ho artinya tidak signifikan

Nilai Ftabel akan dicari dengan menggunakan tabel $\mathrm{F}$ dengan rumus signifikan; $\alpha=0,05, \mathrm{k}=$ jumlah variabel

Mencari nilai $\mathrm{F}_{\text {tabel }}$ menggunakan Tabel $\mathrm{F}$ dengan rumus:

$$
\mathrm{F}_{\text {tabel }}=\mathrm{F}_{(1-\alpha)(\mathrm{dk}=\mathrm{k}),(\mathrm{dk}=\mathrm{n}-\mathrm{k}-1)}
$$

$=\mathrm{F}_{(1-0,05)(\mathrm{dk}=2),(\mathrm{dk}=42-2-1)}$

$=\mathrm{F}_{(0,95),(2,39)}$

Cara mencari $\mathrm{F}_{\text {tabel }}$ : angka 2 adalah angka pembilang angka 39 sebagai angka penyebut, maka di cari dengan interpolasi dengan rumus:

$$
\begin{gathered}
C=C_{O}+\frac{\left(C_{1}-C_{0}\right)}{\left(B_{1}-B_{0}\right)} \cdot\left(B-B_{O}\right) \\
B=\text { nilai dk yang dicari } \\
B_{o}=\text { nilai dk pada akhir awal yang sudah ada } \\
B_{1}=\text { nilai dk pada nilai akhir yang sudah ada } \\
C_{=\text {nilai }} \mathrm{F}_{\text {tabel yang dicari }} \\
C_{o}=\text { nilai } \mathrm{F}_{\text {tabel pada awal nilai yang sudah ada }} \\
C_{1}=\text { nilai } \mathrm{F}_{\text {tabel yang akhir nilai yang sudah ada }}
\end{gathered}
$$

Dari tabel F diperoleh:

$$
\begin{aligned}
& \mathrm{B}=39(\mathrm{dk}=\mathrm{n}-\mathrm{k}-1=42-2-1=39) \\
& \mathrm{B}_{0}=35 \\
& \mathrm{~B}_{1}=40 \\
& \mathrm{C}_{0}=3,27 \\
& \mathrm{C}_{1}=3,23 \\
& C=3,27+\frac{(3,23-3,27)}{(40-35} \cdot(39-35)
\end{aligned}
$$$$
=3.23
$$

\section{Pembahasan}

Contracting Contingency merupakan mengatur kondisi sehingga konseli menampilkan tingkah laku yang diinginkan berdasarkan kontrak antara konseli dan konselor. Metode kontrak juga merupakan bentuk dari managemen behavioral dimana hadiah dan hukuman untuk perilaku yang diinginkan dan perilaku yang tidak dapat dihindari terbentuk.

Metode kontrak dapat berjalan dengan baik ketika ada hubungan komunikasi yang baik pula antara konseli dan konselor, dimana guru dan siswa membuat sebuah kontrak perjanjian untuk mengubah perilaku siswa. 
pada penelitian ini yang menjadi fokus adalah metode kontrak yang digunakan untuk meningkatkan kesadaran siswa pada peraturan tata tertib. Ada beberapa cara yang digunakan oleh guru BK maupun guru mata pelajaran agar dapat meningkatkan kesadaran siswa. salah satunya yaitu menerapkan metode kontrak agar siswa lebih sadar akan menaati peraturan tata tertib yang berlaku di sekolah.

Keberhasilan metode kontrak dalam meningkatkan kesadaran siswa dalam menaati peraturan tata tertib bukan hanya sekedar menjalankan kontrak perjanjian tersebut, tetapi lebih kepada kesadaran siswa dalam menjalani kontrak dan kinerja guru dalam memberikan hadiah maupun ganjaran yang positif kepada siswa agar mereka lebih sadar dalam menaati peraturan tata tertib. Artinya kesadaran akan aturan tersebut telah tertanam dalam hatinya dan menjadi pendorong agar tidak melakukan, jika ingin melakukan sesuatu yang melanggar. Seperti diuraikan Wijaya \& Rusyan (1992:18) bahwa ata tertib merupakan suatu yang terletak didalam hati dan jiwa seseorang yang memberikan dorongan bagi orang yang bersangkutan untuk melakukan sesuatu dan tidak melakukan sesuatu sebagai yang ditetapkan oleh peraturan dan norma-norma yang berlaku.

Setelah dihitung ternyata Fhitung $\geq$ Ftabel atau 4,42 $\geq 3,23$, maka tolak Ho dan terima $\mathrm{Ha}$ artinya terdapat pengaruh yang signifikan antara metode kontrak (Contracting Contingency) terhadap peningkatan kesadaran siswa pada peraturan tata tertib. Dengan demikian, dapat dipahami bahwa metode kontrak memiliki pengaruh terhadap peningkatan kesadaran siswa pada peraturan tata tertib di SMA Negeri 1 Tanete Rilau.

\section{SIMPULAN DAN SARAN}

Setelah dihitung ternyata Fhitung $\geq$ Ftabel atau 4,42 $\geq 3,23$, maka tolak Ho dan terima $\mathrm{Ha}$ artinya terdapat pengaruh yang signifikan antara metode kontrak (Contracting Contingency) terhadap peningkatan kesadaran siswa pada peraturan tata tertib. Dengan demikian, dapat dipahami bahwa metode kontrak memiliki pengaruh terhadap peningkatan kesadaran siswa pada peraturan tata tertib di SMA Negeri 1 Tanete Rilau.

Penelitian ini menarankan kepada Guru BK maupun guru mata pelajaran dapat menjadikan penelitian ini sebagai rujukan dalam meningkatkan kesadaran siswa pada peraturan tata tertib di SMA Negeri 1 Tanete Rilau. Kemudian kepada Pada peneliti selanjutnya untuk lebih mengembangkan dan meneliti lebih mendalam fungsi metode kontrak untuk meningkatkan kesadaran siswa pada peraturan tata tertib.

\section{DAFTAR RUJUKAN}

Abu Ahmadi, 2009, Psikologi Umum. Rineka Cipta. Jakarta

Ezra dan Ezra. 2007. Enhancing Self awareness (http://powercharacter.com/page_smart27juni.html)

Wijaya, Cece \& Rusyan, Tabrani.A 1992, Kemampuan Dasar Guru Dalam Proses Belajar Mengajar Remaja. Rosda Karya. Bandung 
Riduwan. 2007. Belajar Mudah Penelitian.

Alfabeta. Bandung.

Suharsimi Arikunto. 2002. Prosedur Penelitian,

Suatu Pendekatan Praktek. Rineka

Cipta. Jakarta

Fauzan,L. 2016. Kontrak Perilaku. Diakses

melalui

http:/lutfifauzan.wordpress.com/2009/0

8/09/kontrak-perilaku/ update tanggal

29 Maret 2016. 